\title{
INFORMATION BASE FOR DECISION-MAKING AT THE MICRO AND MACRO LEVELS IN AGRICULTURE
}

\author{
Aleksandra Figurek, $\mathrm{PhD}$ \\ Faculty of Agriculture, University of Banja Luka, Republic of Srpska, Bosna and Herzegovina \\ E-mail: aleksandrafigurek@yahoo.com
}

\begin{abstract}
Agricultural activity takes place in a dynamic environment, which is under daily change. It is faced with changes in technology, prices, climate and institutional framework. These changes make an impact on the realization of agricultural production activities, of which depend the results on operations of farmers. One of the basic measures that can help in coping with these changes is to improve agricultural production through the continuous recording of transactions generated on farms. Due to the presence of variable conditions in production, which are often unpredictable and can not be significantly affected by them, it is necessary the each activity in agriculture carefully to plan, to organize and direct toward its goals. In te paper was used the system approach and methods of system analysis. System analysis provided the ability to compose the adequate system in agricultural sector, which offer important informations for farmers. Integration of existing databases relating to this sector at the micro and macro level, on the one hand and data regarding the production capacity and operations of agricultural producers on the other, are one of the measures that may have influence on the adjustment of agricultural policy and the creation of measures which will result in achieving the expected effects. The existence of this information base, which is in addition to the aforementioned sources, based on data relating to the economic indicators about agricultural holdings, is essential for the agricultural sector.
\end{abstract}

\section{KEY WORDS}

Farms; Production and financial data; Integration; Institutions.

A common market for agricultural products, imposed to the agricultural policy makers the task of synchronized planning of agricultural production at national and international level. For its implementation it is necessary to have adequate information on the nature and extent of agricultural production in the state and its distribution by regions. The main prerequisite for the successful planning of agricultural development is the existence of information about resources, constraints and the available capacity for production, and business and economic characteristics of farms. Also, the agricultural sector faces a number of serious challenges: the growing demand for food, there is less space for cultivation because of population growth, the decline in agricultural productivity due to degradation of natural resources. Slof and Argiles (1998) emphasize the importance of the agricultural sector and emphasize the fact that to agriculture should be given more attention by scientists, knowing the importance it has for the population. Just and Zilberman (2002) confirm the importance of information to increase efficiency and improve agricultural production. For farmers, it is necessary to have information about climate and other weather conditions, as well as financial data, which are related to production activities of their farms. The rapid development of the economy and the importance of timely information for a particular activity require the existence of an accounting information system in order to improve operations at the farm itself (Vajna Istvánné, 2000). For its implementation it is necessary to have adequate information on the nature and extent of agricultural production in the state and its distribution by regions. Financial management in agriculture is the bloodstream regarding business of entity in this sector (Santacoloma, Röttger and Tartanac, 2009). If farmers gain control of their finance, it will reflect positively on the organization of agricultural activities on the farms. This means the effective management of the farm, which requires the possession of high-quality production and economic information about business events on the farm (Bernanrd del Homme, 1997). Information which derived from the available manufacturing processes can be seen as an important factor in the interaction with 
other factors of production such as land, labour, capital and can contribute to more successful business holdings. Also, the information distributed to farmers through the media, educational institutions, and advisory services, are a function of enrichment - extend the knowledge of farmers so that they are able to make better decisions based on that information, to take advantage of market opportunities and to continuously manage changes in terms of their production activities.

The combination of information about past events and projected financial forecasts contained in the plans, allows timely adjustments and quality control complex production processes in agriculture. In the absence of quality information, and due to the lack of systematic collection of original accounting data from farms, agricultural policy makers dont have a strong foothold in practice. They risk to enactment the wrong measures, which can cause improper and even opposite of the desired effect. In this regard, it is necessary to take appropriate measures with regard to timely review the production activities of farmers and their involvement in recording production and their results.

\section{METHODOLOGICAL ASPECTS}

Methodological and applied nature of the paper required the use of multiple research methods. The system approach and methods of system analysis were used. Selected methodological concept through a systematic approach had the task to enable the formation of a systematic form of the comprehensive information base in the agricultural sector. Using the system analysis, as well as methodological procedure, provided the ability to decompose the system to individual components with the aim to study their mutual influence of contribution to agriculture.

\section{INFORMATION FOR DECISION-MAKING ON THE FARM}

With the development and improvement of technology, certain requirements in terms of accuracy and integration of production planning and control activities were imposed in front of the agricultural sector. Prior to the commencement of the planned production activities, it is necessary to examine the factors that may reduce the expected yield or results of operations (verification of machinery, biological and meteorological conditions, etc.). Agricultural producers should have the ability to make timely and appropriate decisions in order to better organize their production activities. Decision theory provides a framework to define the stages in the decision-making process: problem identification, generation of alternative solutions, selection of an appropriate solution and its implementation (McKenna and Martin-Smith 2005) ${ }^{1}$. Farmer Decision Support Framework (FDSF) through the appropriate information flow defines guidelines whose use is trying to facilitate the farmers to make timely and appropriate decisions regarding their production activities. This framework can serve as a basis for the development of an integrated system of accounting information in the agricultural sector (macro level) and management systems of production activities at the farm (micro level), which provides structural support to the farmers in their decision making process. The diagram 1 presents the information processes and the interaction between the key players who have information which are of great importance to farmers in decision-making.

Professional environment of farmers is characterized by the activities of other actors in the agricultural sector, such as advisors, retail chains that sell agricultural products farmers' associations, international consultants and national policy frameworks. Informal environment includes family farming friends, neighboring farms. Communication and cooperation between farmers and their professional environment has a significant share of the business and achieving positive financial results. Characteristics that affect communication and cooperation between farmers and individual participants are identified and classified into a

\footnotetext{
${ }^{1}$ McKenna R. J., and B. M., Martin-Smith (2005): Decision making as a simplification process: New conceptual perspectives. Management Decision. 43: 821-836.
} 
group professional environments. Farm size affects the forms of communication and cooperation, then age and educational structure of the holders of agricultural activities on the farm, also makes a significant impact on how will be the cooperation between these two environments, and on the process of decision-making by farmers.

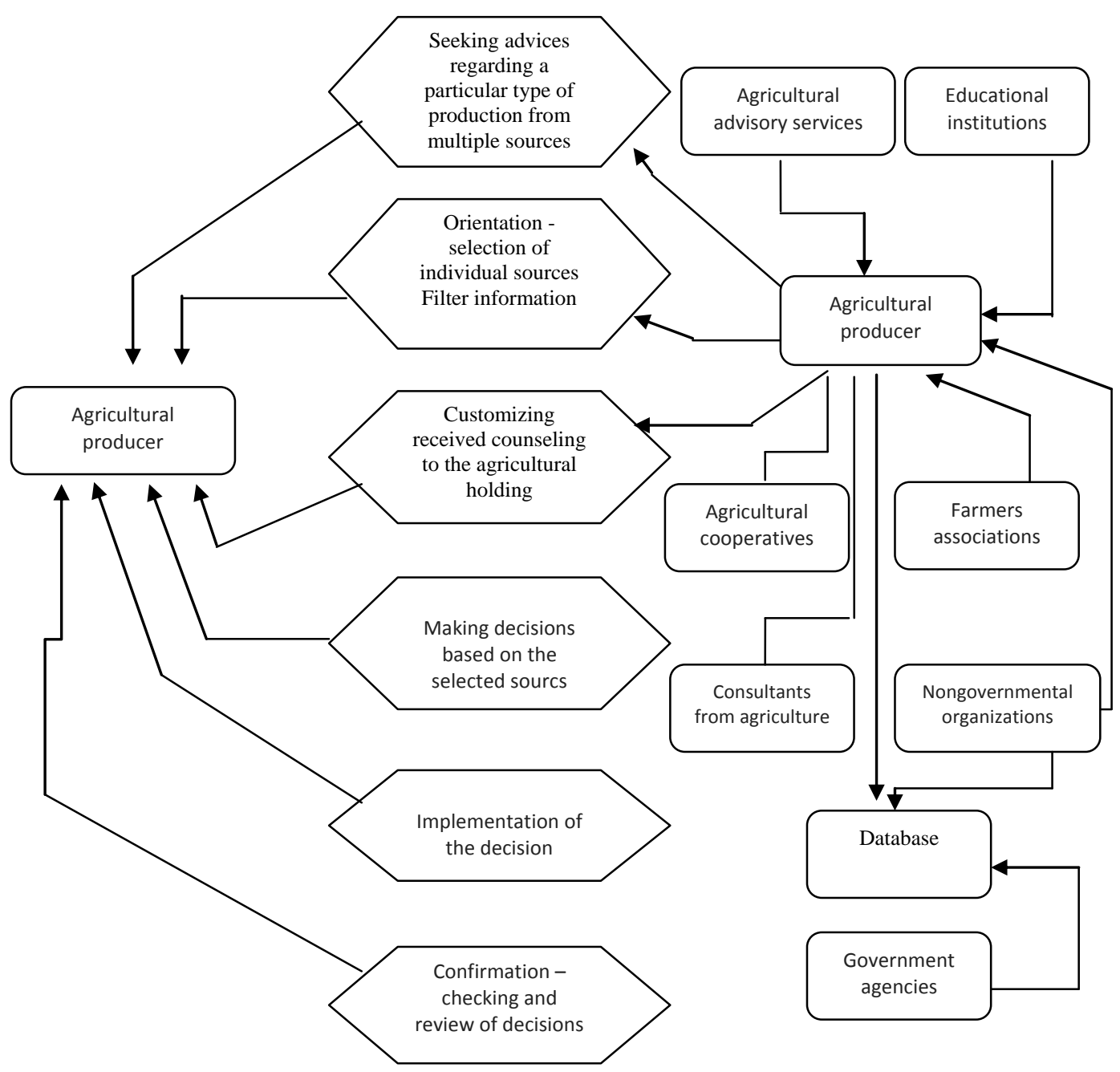

Diagram 1 - The decision making process in the agricultural sector

As farmers are required to make decisions within their manufacturing operations, it is essential everyday to have data on the amount of funds invested in each production cycle on the one hand and actual operating results on the other side. It should be noted that the activity of observing and monitoring the results arising from agricultural activities is a key factor in achieving a successful business of farms. In this way, the task which is related to the monitoring results, can be formulated in accordance with the actual needs of the situation on the farm, particularly in terms of costs and benefits on the holding. During the planning and implementation of production activities, the central aspect is collecting the information about the current and future state of the farm. Monitoring the production processes and individual activities on the farm, then costs which causes the production processes, can facilitate the control or management of the farm. To plan and control production activities, subsequent decisions which should be undertaken on the farm, are of great importance and should be brought with great responsibility, and on the basis of well-planned future activities. The diagram 2 presents the flow of information or the process of using information from the farmers. The data flow between the various components of the system and use of the 
collected data is a complex process that requires the providing of information from several sources that are inputs. In order to use information adequately, it is essential that the agricultural producers possess basic knowledge of farm management. They should be used for making timely decisions that are critical to the management of production processes.

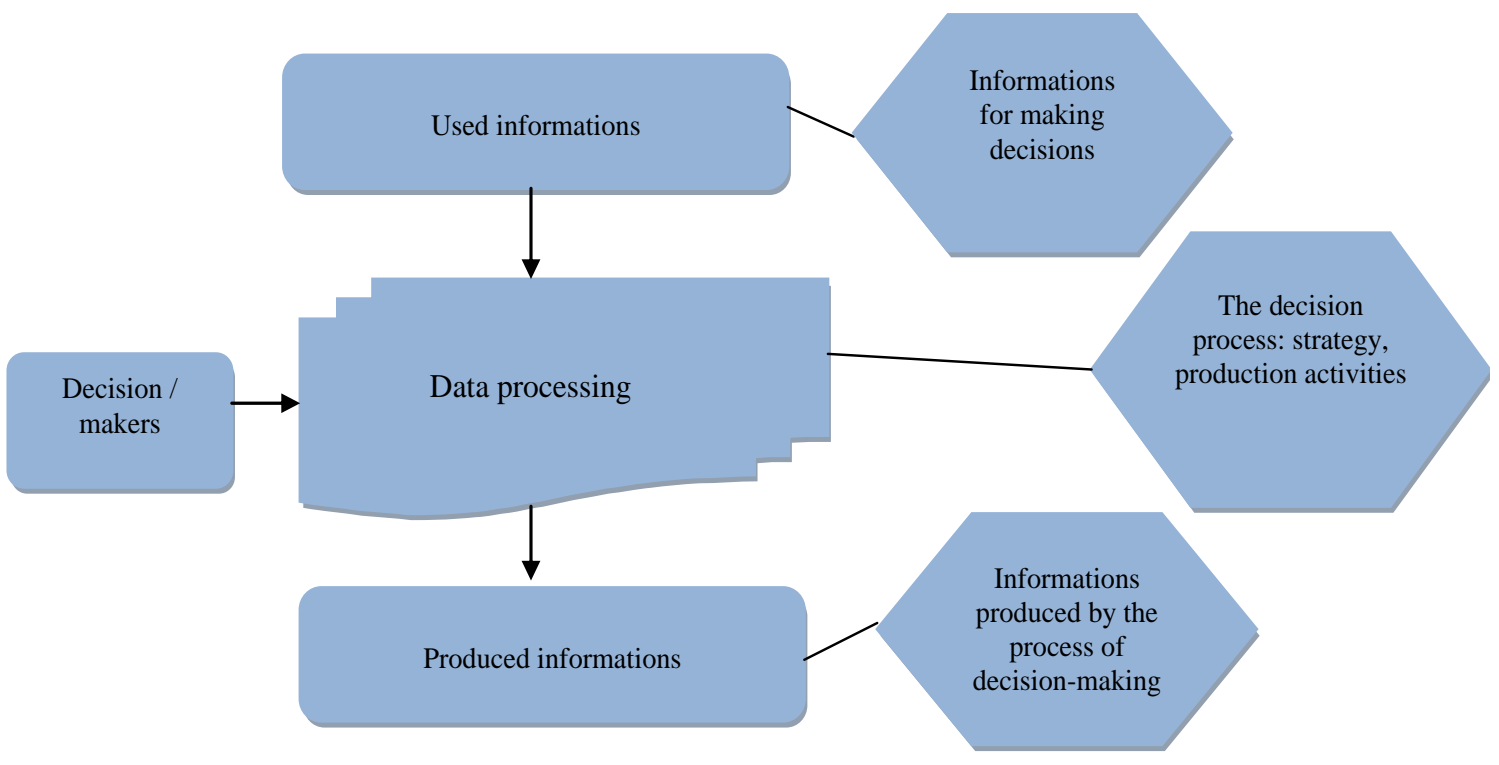

Diagram 2 - The flow of informations

The main task in the analysis of information flow defined model is a consideration of all the factors that can have a sizable impact on the farmers. This model starts from the farmer whose decisions and choice of information sources is the basis of the whole system. If he focuses in addition to internal, also on obtaining external information, the chances of improving organizational and farm management functions are higher. Achieving greater organization in the implementation of productive activities, enabled farmers to gain insight into their production capabilities and a better assessment of indicators that indicate the success or failure of production activities (Sorensen, Fountas, Nash, Pesonen, Bochtis, Pedersen, Basso, Blackmore, 1999). This approach leads to better control of manufacturing processes, as well as enhanced opportunities to achieve greater quality of agricultural products, manufacturing traceability, increasing market share and so on. Control of the operations, combined with a database of previous business results represent the quality support in decision-making. In this sense, to the results of the production process, greater impact can achieve an adequate system of organization and control of the process, than some agricultural activities. Schedule of agricultural operations should be connected with the system for monitoring the effects arising from the undertaking production activities.

Recording of data on production processes (quantities and prices of consumed feed, fertilizers, harvested area, yield, revenue from the sale of agricultural products), represents the basic pre-condition to coordinate production activities with previously created budget. (Oltmans, Klinefelter and Frey 1992). As decision makers, farmers have to continuously work on problems that arise in a complex agricultural-manufacturing sector, which has always been dependent on many factors, which are often difficult to predict and control. (Parker, Campion, Kure, 1997). If in a given period appear discrepancies between planned and actual activities, data recorded in the past can serve the purpose of identifying the critical points registered in the previous production cycles, and it is necessary in the future to adjust the production plan of activities and budget or financial means on the farm. By the heterogeneous or mixed farms, due to the presence of several types of agricultural production, there is a need for a more complex approach in the measurement and assessment of the results of their entire business. These farms produce various kinds of 
agricultural products, and use a variety of inputs that need to be recorded and properly allocated depending on the type of agricultural production. This concept represents a detailed approach to modeling informations, which enable the creation of desirable information base for decision-making at the micro and macro level.

In order to make an adequate information base and to ensure the proper flow of information that it needs in order to efficiently implementation of manufacturing processes on the farm, it is necessary that farmer express the willingness to adopt new work practices in terms of continuous recording of the results of production activities, and if it necessary, pass additional training in learning new skills. Continuous recording of economic events that follow a production process is of crucial importance for the further involvement of material and financial, and human resources. Owning accurate records (Heidhues and Patel 2008) allow to comparing all the costs (labor costs, etc.). Increase or decrease of income, changes in prices of raw materials and finished products, changes in the volume of production etc. (Somiari, 2008). In this case, it is possible to achieve a concept that is based on reducing production costs and increasing revenue. Thereby, farmers will reduce existence of critical points and unnecessary costs incurred due to improper and irrational exploitation of natural resources. Information on agricultural production related to the quantity production, ie. the yield and the dynamics of consumption inputs from the quantities of seeds, fertilizers, the protective aids, the time spent by the paid and their own labor, are of great importance for the planning and organization of the next production activities, with the aim of reducing the risk of getting a lower yield than expected. The yields in crop production are greatly influenced by meteorological or weather factors, which can greatly affect the achievement of lower yields, and it is required that farmers in organizational terms, reviewing its past operations and economic results, achieve influence for the better results of operations of the farm.

\section{INTEGRATING DATA AT THE MACRO LEVEL}

Decision-making in the agricultural sector at both the micro and macro level based on the quantitative and qualitative informations about realisation production activities on farms. For this reason it is necessary to have detailed information about their business in order that decisions came appropriate and on time. Quantitative and qualitative data relating to the agriculture sector and their exchange between different institutions in order to monitor the current agricultural and food conditions and requirements, provide information base to the government in making decisions related to agriculture. There are a number of participants in data collection, universities, including research institutes, extension services, nongovernmental organizations, farmers' associations and other institutions, which, within the framework of its activities and the realization of daily activities, have an interest in owning the data from the agricultural sector.

In the concept of an information system, the key role of institutions is contained in the generation, transmission and receipt of information through information flows and their respective relationship which is reflected in the cooperation between these institutions. Data pertaining to this sector are important for traders, suppliers, distributors of agricultural inputs, micro-credit and financial institutions, investors and other service providers or their customers, whose interest in owning a quality assessment of opportunities and promising types of production in the agricultural sector. Activities related to data collection are not always the responsibility of one institution: for example, the Statistical Office has an obligation to collect data that are based on the cultivated land, the average yield on the one hand, while certain research and analysis related to the agricultural production carried out by the relevant ministry or research institutions. In these circumstances, the establishment of coordination between different institutions and distribution activities, which will be aimed at gathering data and creating an integrated database in the agricultural sector, is the basis for quality decisions, and at the macro and micro level.

Any action of agricultural extension services are mainly oriented to provide consulting services through the provision of technical information. Advices, which are related to the 
operation of agricultural holdings and the analysis of their previous economic activities, should certainly be implemented within the work of the agricultural extension service. One of the main objectives of agricultural extension services should represents support to the rural population in terms of improving their living standards by increasing the efficiency of agricultural production and increase the revenue generated on the farm. In the achievement of these goals, it is necessary to put a lot of effort, knowledge and time by performing the following tasks:

- Information - providing information to farmers about the economic and market conditions relating to the sector in the country and the region, then the information on modern technology in agriculture.

- Advisor - professional support to the producers in solving problems related to certain production activities including all types of agricultural production

- Dissemination - the application of the latest technological innovations related to agricultural practices.

- Education - training and achieving a higher level of knowledge and professional skills of farmers.

If the goal is to maintain the achieved level of production or the achievement of its higher levels, it is important to record the quantity and value indicators related to embedded inputs and outputs achieved in each type of agricultural production. If we look the aspect of agricultural commercialization and increase the number of commercial farmers, informations relating to their operations are really necessary and represent a strategic resource to support decision-making at various levels. Better results in the agricultural sector requires the existence of an adequate system of accounting information (Demiryürek, 2010). Identifying the risks, needs and demands that farmers face with, is of great importance in the process of the formation of the aforementioned information system in the agricultural sector. In the process of the formation of the aforementioned information system in the agricultural sector, it is of great importance to identify risks, needs and demands that farmers face with.

Despite the small amount of time which farmers have, planning and organizing the production activities and recording of their data about business events on the farm, could help in increasing profits, if using these activities effectively. Records on the farm have four important characteristics which are necessary for the successful operation of agricultural holdings: (1) Tool service, (2) diagnostic tool enable and consideration of critical points in the business and identify the problems that limit the increase in revenue, (3) an indication of progress, and (4) future planning of production processes (Brannstrom, 2011). Improving the organizational capacity of farmers and the establishment of the benefits regarding of competition in the market, depends primarily on the possession of adequate and timely informations. Adequate and timely informations are of great importance for business of agricultural holdings, given the fact that the overview of past activities related to the production process, affect the planning of future activities and finaly financially result. The task of this system is to identify the limiting factors that affect the farm business, and based on a detailed review of the situation of all production resources, to plan appropriate and timely changes in the production activities.

\section{THE FUNCTIONING OF THE SYSTEM}

Making decisions based on quality information has a significant feedback effect on accelerating the development of agriculture, and bringing it closer to the standards of developed countries. The decision making process is a major responsibility of all stakeholders in the agricultural sector and should be based on good database, which integration contributes to the ensuring its quality. Prerequisites for further progress in this sector and the implementation of appropriate and timely actions, involves an integrated approach in terms of getting information from multiple sources. This suggests the need for establishing of appropriate integrated information system as a comprehensive information base, which in their structure includes data from a number of sources and providing relevant information to a particular sector, with a view to making appropriate and timely decisions. 
The structure of an integrated information system indicates the importance of the process of data integration, which is the basis of information systems in agriculture (Kabat, Naiken and Narain, 2000). Establishment of measures and designing future policies in the agricultural sector requires the existence of productive and economic data on agricultural holdings. Establishment of an integrated system of accounting informations at the micro level requires intensive participation of farmers, for the collection of certain data about the inputs values, and also about output depending on the type of production. The data collected from farms constitute a comprehensive base of information about activities in agriculture. This database is based on records on the business activities on farms and is crucial for making precise and timely information reports for this sector:

- Balance sheet and income statement of farms;

- Statement of Cash Flows;

- Analytical calculations of production;

- Cumulative calculations by type of production, by regions;

- Other analytical reports.

Balance sheet, income statement, statement of cash flows, are based on data relating to a single accounting year, while analytical calculations form in order to show the results of operations, which includes the production cycle. In this regard, it is important to note the differences between the calculations in crop and livestock production (in crop production, a significant portion of the costs incurred in one year, and revenues are realized after implementation of output in another year). For the purpose of comparison of different crop, fruit and other cultures, there is possibility to make aggregate calculations by type of production, by region, etc., which also represent an important information base in perceiving and comparing costs and actual results. In order to form a complete picture of the business operation of farms, of great importance is the development of the analytical indicators of success, so that producers have an opportunity to look at which the production and the culture or the type of livestock production provide greater or smaller financial effects of the implementation of their production activity.

Integrated system of accounting information in the agricultural sector through the analysis of the results of agricultural activities and farms in the whole, aims in a systematic and comprehensive way to encouraging the development of the agricultural sector. This implies the involvement of other institutions, which taking into account their core business, have access to information that achieve integration with other information which are key to the development of the sector. Combining another information sources with information derived from operations on the agriculture farm, offers farmers a good basis for decision making. The process of integration of internal and external data sources provide them more efficiently future business activities and timely coordination of production activities. Taking into account the data derived from the micro and macro levels, this integrated approach should systematically and comprehensively encourage producers to use inputs more precise and adequate use of financial resources that are generated by the sale of individual and total output.

Generating data from different sources is intended to encourage the efficient operation of the system, which in this case is a farm, and that the use of the aforementioned information achieve synergy which will be transferred from the micro to the macro level. Use of information and its timely implementation in policy formulation, then in program planning, monitoring and evaluation of their national level, represent an adequate strategy. Information management at the macro level is an important prerequisite to properly encourage farmers to achieve greater efficiency and achieve better business individual results, which will contribute to better results at the micro level, ie. particular synergy effects will contribute to the overall development of the agricultural sector. Reasons for achieving lower current productivity in this sector are numerous, but the lack of accounting records by farmers is one of the important reasons. Agricultural producers are not required, but also no habit of keeping records in the production activities, and cash transactions that are carried out in the procurement of raw materials and payment of labor involved, but also the sale of agricultural products. Since they do not have records regarding these business events on the farm, as a 
result, farmers do not have insight into the costs and income on their own farm, and forecasts of its operations and future actions taken based on the referential data resulting from their memories on realized production activities. Recording business events, facilitate farmers understanding of the real situation, which is to encourage him to take corrective measures in order to achieve the desired productivity, efficiency and profitability as well as the basic principles of partial operations. Achieving efficient operations and adequate management resource on the farm, the farmers realized by recording and tracking production activities the value of invested assets and gross value of production. It is on the aforementioned elements and purpose based accounting information system that aims to provide such data to make timely decisions. This system must be support of agricultural producers and their current efforts to make appropriate and timely decisions, in terms of adapting the volume of production to market needs. In order farmers were able to respond and react to certain circumstances that reflect the uncertain environment, they must at all times be ready, based on their records of completed evaluation of the economic situation of households, to make the best decision at the moment. Data derived from integrated information system are extensive and include: structure of farms by type of agricultural production, by the region, the volume of production, its value, the data on hiring labor, purchase prices of inputs, and so on. In addition to the government and the ministry, users of this informations include agricultural producers, agricultural cooperatives, agricultural advisory services, research institutions, economic chamber, NGOs, etc. Beside data about farmers business activities, of great importance are also data that arise from external sources, which indirectly exercise influence on the operations of farmers. Planning activities and their implementation within an integrated system of accounting information, requires efficient organization, personnel who have sufficient knowledge to implement activities at all levels.

\begin{tabular}{|c|c|c|}
\hline Micro level - Agricultural holding & \multicolumn{2}{|c|}{ Macro level - The agricultural setor } \\
\hline 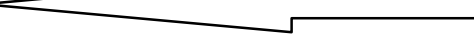 & & ᄂ \\
\hline $\begin{array}{l}\text { Record details of the agricultural } \\
\text { holdings activities }\end{array}$ & $\begin{array}{l}\text { Data collection } \\
\text { Data analysis }\end{array}$ & $\begin{array}{l}\text { Plan future activities created } \\
\text { using data from multiple sources }\end{array}$ \\
\hline $\begin{array}{l}\text { Classification of data according to } \\
\text { regional representation }\end{array}$ & $\begin{array}{l}\text { Data integration: } \\
\text { Ministry of Agriculture, }\end{array}$ & $\begin{array}{l}\text { Analysis of the measures and } \\
\text { activities, }\end{array}$ \\
\hline $\begin{array}{l}\text { Classification of data according to the } \\
\text { type of production }\end{array}$ & Agricultural advisory services, & $\begin{array}{l}\text { Comparison of the effects } \\
\text { achieved in the implementation } \\
\text { of the policies for the agricultural }\end{array}$ \\
\hline $\begin{array}{l}\text { Classification of data by area (ha) and } \\
\text { the number of livestock }\end{array}$ & Statistical Office, & $\begin{array}{l}\text { Identifying real needs and } \\
\text { perform the necessary }\end{array}$ \\
\hline $\begin{array}{l}\text { Classification of data according to } \\
\text { business performanc of agricultural } \\
\text { entities in the agricultural sector }\end{array}$ & $\begin{array}{l}\text { Farmers associations, } \\
\text { Agricultural cooperatives. }\end{array}$ & $\begin{array}{l}\text { Interventıons in terms of } \\
\text { correcting certain activities. }\end{array}$ \\
\hline
\end{tabular}

Diagram 3 - Lintegrations of macro and micro level in the sector of agriculture

The exchange of information between government departments and agencies, farmers and other stakeholders in the agricultural sector, contribute to a more awareness and timely face with certain issues from farmers themselves at the micro level, and the government and the ministry at the macro level, and if they do not timely perceive and take appropriate measures, then may give rise to a problem whose solution requires a longer period of time. 
Thus, the synergistic effect, which is achieved exchanging of informations between the micro and macro level should affect the higher production efficiency and better organization of farmers in the planning and design of their production activities.

\section{CONCLUSION}

Decision-making and management of agricultural activities with efficient data processing and their transformation into useful information for farms, represent an important aspect in terms of efficient management on micro and macro level, considering the entire agricultural sector.) In order to make right strategic decisions in the agricultural sector, it is necessary to have quality production and economic informations from agricultural holdings. Economic indicators on the production activities of farmers are the basis for the planning of their future business activities. Adequate control of manufacturing processes enables farmers to achieve significant market share, and to be more flexible when it comes to market needs. Using existing resources at the farm in conjunction with other inputs that farmers must procure, should be in accordance with the available financial resources. Establishment of integrated accounting information systems, in the field of agriculture, is extremely important in a globalized world. Informations allows farmers to have daily access to the course of its business activities, and the agricultural policy makers to monitor and direct the development of the agricultural sector. Lack of information system, which could provide highquality production-financial informations in the field of agriculture, is a very serious limiting factor in the development of the agricultural industry in each country. The purpose of existence of the accounting information system is reflected in the transformation of inputs (knowledge of relevant business events) into outputs (business informations), which is required to make quality management decisions at all levels. Produced information (their quantity and quality) also represent the criterion based on which is possible to measure the effectiveness of accounting information systems (the ratio between the value of output and the costs incurred for their production). At the micro-level, high-quality information are the basis for making good business decisions and improve efficiency of farms themselves. At the macro level, the collected accounting informations allow the derivation of valid economic indicators, and on the basis of their analysis, the adoption of appropriate measures in various areas related to the agrarian sector (agricultural, customs, credit, monetary policy, etc.). Policy makers in agricultural sector have available quantitative indicators of the conditions and results of operations of farms.

\section{REFERENCES}

1. Agrahari, A., Tripathi S. (2012). A Theoretical Framework for Development of Decision Support System for Agriculture, International Journal of Engineering and Science, Vol. 1, Issue 6: 50-55

2. Armstrong, L, Diepeveen, D and Vagh Y. (2007). Developing an information-driven ICT framework for Agriculture, Data mining can empower growers' crop decision making T2: Technology and Transformation. 3rd Transforming Information and Learning Conference. Perth, Edith Cowan University.

3. Arnold W. Oltmans, Danny A Klinefelter and Thomas L. Frey (1992). Agricultural financial reporting and analysis, AFRA, Niles, III.: Century Communications, c1992.

4. Brannstrom, A.J. (2011). Using Farm Records Effectively for Business and Financial Management, Faculty Associate, UW Center for Dairy Profitability,http://www.uwex.edu/ces/search.cfm?searchterm=Brannstrom\&scope=http\% $3 \mathrm{~A} \% 2 \mathrm{~F} \% 2 \mathrm{Fwww} . u w e x . e d u \% 2 \mathrm{Fces}$

5. Del'homme B. (1997). Information and decision in agriculture : how relevance is management diagnosis is improved by an expert system - Proceedings of the First European Conference for Information Technology in Agriculture, First Conference, Copenhagen, EFITA, 221-227. 
6. Demiryürek, K. (2010). Information systems and communication networks for agriculture and rural people, Agric. Econ. Czech, 56, (5): 209-214.

7. Heidhues, E., Patel, C. (2008). The Role of Accounting Information in Decision-Making Processes in a German Dairy Cooperative, 10th International Conference on Accounting \& Business, Shanghai.

8. Just, D., Zilberman, D. (2002). Information Systems in Agriculture, ARE Update, Vol. 6, No. 1, 3-6.

9. Kabat, L., Naiken, L. and Narain, P. (2000). Data integration and its role in the development of better agriculture and food information system, International Conference on Establishment Surveys, Integrating Agriculture and Food Statistics: National and International Perspectives, Buffalo, WB symposium.

10. McKenna R. J., and B. M., Martin-Smith (2005). Decision making as a simplification process: New conceptual perspectives. Management Decision, 43: 821-836.

11. Parker, C.G., Campion, S., \& Kure H. (1997). Improving the uptake of decision support systems in agriculture, Proceedings of the First European Conference for Information Technology in Agriculture, Copenhagen, Denmark, Copenhagen: EFITA, 129-134.

12. Santacoloma P., Röttger A., Tartanac F. (2009). Business management for small-scale agro-industries, FAO Agriculture Management, Marketing and Finance Service Rural Infrastructure and Agro-Industries Division, Food and agriculture organization of the united nations, Rome.

13. Slof, E. J., Argiles, J.M. (2000): New opportunities for farm accounting, The European, Accounting Review 10 (2), Barcelona, 361-363.

14. Somiari, F.R. (2008). Farm menagement and record keeping Monitoring and evaluation officer, third national fadama development programme, Rivers state coordinating office, ADP premises, Port Harcourt.

15. Sørensen, C.G., Fountas, S., Nash, E., Pesonen, L., Bochtis, D., Pedersen, S.M., Basso, B., Blackmore S.B. (2010). Conceptual model of a future farm management information system, Computers and Electronics in Agriculture 72, 37-47.

16. Scheuerlein, A. (1997). Finanzmanagement für Landwirte, Verlags Union Agrar, München.

17. Vajna Istvánné Tangl Anita (2000). Comparison the informations from the hungarian accounting system to the reqiremets of the european union's farm accontancy data network, Ph.D. thesis, Szent István University - Gödöllõ. 